\section{Effects of camphor oil addition to diesel on the nanostructures and} oxidative reactivity of combustion-generated soot

Pranay P. Morajkara,b, Gerardo D.J. Guerrero Peñac, Abhijeet Raja, ${ }^{*}$, Mirella Elkadid, Ramees

K. Rahmane, Akshay V. Salkarb, Avin Pillayd, Tharalekshmy Anjana, Min Suk Chac

aDepartment of Chemical Engineering, The Petroleum Institute, Khalifa University of Science \& Technology, Abu Dhabi, U.A.E

bSchool of Chemical Sciences, Goa University, Taleigao Plateau, Goa, India

cClean Combustion Research Centre, King Abdullah University of Science and Technology,

Thuwal, Saudi Arabia

dDepartment of Chemistry, Khalifa University of Science \& Technology, Abu Dhabi, U.A.E eDepartment of Chemical Engineering, University of Central Florida, Orlando, US

\section{Abstract}

Less viscous and low cetane (LVLC) fuels have emerged as the promising alternative fuels or additives to fossil fuels. Camphor oil is one such potential LVLC fuel currently under consideration. However, it's sooting propensity and subsequent effects on soot nanostructure, when blended with diesel, are not well understood. In this work, the effects of camphor and camphor oil addition to diesel on the sooting propensity, soot oxidative reactivity, and the chemical composition, structural disorders, and the morphology of soot particles are studied using a diffusion flame. The chemical and the microstructural changes in soot are investigated using several experimental techniques such as energy dispersive X-ray spectroscopy, high resolution transmission electron microscopy, Raman and electron energy loss spectroscopy, and powder X-ray diffraction, while the oxidative reactivity is studied using thermogravimetric analysis. The activation energy for $\mathrm{O}_{2}$-induced soot oxidation during the initiation stage shows a significant reduction in its value with the addition of camphor and camphor oil to diesel, which were $220 \mathrm{~kJ} / \mathrm{mol}$ for diesel soot, $175 \mathrm{~kJ} / \mathrm{mol}$ for $5 \%$ camphor/95\% diesel soot, and $150 \mathrm{~kJ} / \mathrm{mol}$ for $10 \%$ camphor oil/ $/ 90 \%$ diesel soot. The blending of camphor and camphor oil with diesel results in soot with smaller fringe length and primary particle diameter, but increases the fringe tortuosity, the degree of crystal disorder, and the amounts of oxygen functionalities and aliphatics in soot. These physico-chemical changes in soot are used to explain the observed trend of oxidative reactivity. This study successfully demonstrates the potential of terpenoid keto compounds with characteristic bicyclic ring structure in improving 
oxidative reactivity of combustion derived soots as desired in diesel particulate filter technologies.

Keywords: Soot; Nanostructure; Oxidative reactivity; Camphor oil; Diesel.

*Corresponding Author. E-mail address: abhijeet.raj@ku.ac.ae. Phone: +971-2-6075738.

\section{Introduction}

The majority of the ever-increasing demand of society for energy is fulfilled through the combustion of fossil fuels such as diesel and gasoline. Diesel, in particular, has served as one of the most important fuels for on-road and off-road transportation industry [1]. However, due to the technological limitations, its inefficient combustion results in the emission of gaseous pollutants such as $\mathrm{CO}_{\mathrm{x}}, \mathrm{NO}_{\mathrm{x}}$, and $\mathrm{SO}_{\mathrm{x}}$ and solid state pollutants such as soot [2]. Soot is composed of a series of polycyclic aromatic hydrocarbon (PAH) compounds, randomly stacked together in the form of disordered graphitic nano-crystallites [3]. Due to their physically and chemically stable structure, the constituent PAHs are classified as persistent organic pollutants (POPs) [4]. The PAH nano-crystallites are known to bio-magnify and bio-accumulate in the environment causing fatal diseases such as skin and pulmonary cancer [5]. The use of diesel particulate filters (DPF) has by far been the most practical solution to this problem, and is being implemented in developed countries. However, due to the high cost involved, such a technology does not find popularity among developing nations.

Biofuels produced from non-edible sources such as waste cooking oils, animal fats, algae, and seed oils such as Jatropha and Karanja that grow on waste lands [6-9] are being considered as promising alternative fuels or fuel blends to fossil fuels. Fuel modifications using these biodiesels, methyl esters in particular (obtained from the transesterification of biomass), have the capability to reduce soot emission, while simultaneously maintaining the required energy efficiency [10-12]. It has been reported that the presence of oxygenates in the fuel additives, their chemical structure, and their physical properties such as density, kinematic viscosity, and cetane number play a vital role in inducing increased oxidation rate of diesel fuel, thus reducing soot production in combustion engines [13,14]. Moreover, it is also desired to enhance the regeneration efficiency of DPF by altering soot nanostructures in a way that facilitates its faster oxidation once captured in DPF. For instance, Yehliu et al. [15] studied the nanostructure of soot obtained from diesel and biodiesel blends, and unravelled the presence of a large percentage of shell-core type nanostructure using high-resolution transmission electron microscopy (HRTEM) images. They attributed the high reactivity of soot from biodiesel blends 
to this disordered shell-core structure of soot. A similar observation was made in other studies $[16,17]$. Several investigations have correlated the presence of high oxygen content and large surface area of the biodiesel-derived soot to its higher rate of oxidation $[18,19]$. Furthermore, the effect of dilution of diesel with the addition of biodiesel and the relative significance of oxygen content has been statistically studied by some research groups [20]. It has been validated that the oxygenated functional groups in biodiesel play a crucial role in reducing soot production. Moreover, a high oxygen content in soot leads to its high oxidative reactivity. However, there are also reports that contradict this observation. Yehliu et al. [15] found no significance of oxygen content in soot to its oxidative reactivity, and instead attributed the reactivity to the disordered structure of soot rather than the oxygen content. The effects of the amorphous nature of soot and the degree of lattice disorder have been evaluated using XRD and Raman analyses by several researchers, where these crystal defects have been shown to have a significant effect on the improved kinetics of soot oxidation [5,21,22]. Further studies signifying the influence of the chemical structure such as the carbon chain length of the methyl esters, the position of the $\mathrm{C}=\mathrm{C}$ bond, and the presence of the number of methyl group substituent on aromatic rings are available in the literature [23-25]. The increase in the chain length in methyl esters enhances the sooting tendency, but reduces soot reactivity. The position of the $\mathrm{C}=\mathrm{C}$ also influenced the soot reactivity, while the methyl substitution in aromatics decreases the soot oxidation rate. More recently, the studies on the oxidation of soots derived from diesel, biodiesel, and their blends over $\mathrm{Ag} / \mathrm{SiO}_{2}, \mathrm{Ag} / \mathrm{ZnO}$, and $3 \% \mathrm{Ag} / \mathrm{CeO}_{2}$ have reported their excellent catalytic effects in oxidizing soots [26,27], and further research is being conducted to improve their efficiency for their possible application in DPF technology.

Since the above studies suggested that the blending of diesel with biodiesel is efficient in reducing the emitted pollutants while maintaining energy efficiency, a great deal of research focus has been devoted on the search for effective and economical methods to convert biowaste into biodiesel over the past decade. Recently, the photocatalysis-driven synthesis of biodiesel using $\mathrm{Cr} / \mathrm{SiO}_{2}$ catalyst has shown promising results in this regard [28]. However, many challenges still remain to be addressed [29-31]. Recently, a new class of fuels, extracted from bio-based renewable sources, which can be utilized directly as neat fuels in combustion engines without their conversion into methyl esters, are being looked upon as a possible solution to the above problem [32]. The potential candidates for such fuels are the essential oils such as eucalyptus, pine, lemon, and orange oils [33,34]. Camphor oil is one such biofuel, which is currently being studied by some research groups $[35,36]$. It is an essential oil, traditionally extracted from the Cinnamon Camphora tree in most regions of Asia. It is 
available in four grades: white, brown, yellow, and blue camphor oil. The white grade is the most commonly available one, with primary chemical components as Camphor ( 50\%), Linalool ( 23\%), 1,8 Cineol ( $11.5 \%)$, and some minor terpene derivatives [37,38]. On the other hand, solid camphor is obtained by recrystallization from camphor oil, which allows exclusion of the above listed secondary components. In the fuel sector, it is classified into a new class of fuels called less viscous and low cetane (LVLC) fuels. The LVLC fuels are reported to improve fuel/air mixing, fuel evaporation, and fuel atomization in CI engines. Moreover, these fuels offer suitable ignition delays, which in turn allows reduced fuel-to-air ratio to improve combustion efficiency and reduces soot formation [34,39]. For instance, the twin-cylinder compression ignition engine studies under full load condition with camphor oilblended diesel, conducted by Subramanian et al. [35], reported an improved brake thermal efficiency, which is an indicative of the effective conversion of the chemical energy stored in fuel into mechanical energy. The engine experiments, conducted by Kasiraman et al. [36], involved the mixing of less viscous camphor oil with highly viscous cashew nut shell oil that resulted in the improved physical properties of the blend and better engine performance. Thiyagarajan et al. [40,41] investigated the blending of camphor oil with Karanja biodiesel and found that the engine performance was improved with a reduction in $\mathrm{CO}_{2}$ emission, although NOx emission was elevated. Since camphor oil has a low cetane number, its blending with other fuels such as diesel or biodiesel reduces the cetane number of the blend. In such cases, cetane enhancers such as dimethyl ether, dimethyl carbonate have been used in conjunction to improve engine performance $[42,43]$. While the research on improving the engine performance and lowering pollutant emission with camphor oil blended fuels continues to grow, no studies are available in the literature on the nanostructural properties and oxidation kinetics of soot obtained from camphor oil-diesel blends. More importantly, camphor belongs to a special class of naturally occurring organic compounds called the terpenoid ketone family with a characteristic bicyclic ring structure and the presence of keto group, which can be utilized to modify the soot nanostructure of the blended diesel fuels for improving its oxidative reactivity as desired in diesel particulate filter technology. Such an investigation could open up new doorways for tailored synthesis or isolation of naturally occurring terpenoids for large scale utilization in designing advanced bio fuels. Since it is known that, in several combustion systems such as diesel engines, wall wetting assisted, diffusion-driven processes govern soot production rate, soot produced from a diffusion flame could serve as a suitable representative of those processes, and the study of the changes in the physical and chemical characteristics and the reactivity of soot particles could provide an insight into their formation and oxidative 
removal efficiency in engines with DPF. This provided the motivation for the present study to determine the sooting tendency of camphor oil-diesel blends, while simultaneously investigating the modifications in soot nanostructures and its influence on the oxidative reactivity of soot which can improve the efficiency of DPF technology.

\section{Experimental details}

The smoke points of diesel (D), camphor solid-diesel blends (CD), camphor oil (CO), and camphor oil-diesel (COD) blended fuels were measured using an American Society for Testing and Materials (ASTM) standard smoke point apparatus (model number RAP172, developed as per ASTM D1322 standard [23]) at atmospheric pressure. The camphor oil (grade: white, > 99\% purity) and camphor solid (> 99\% purity) were purchased from Sigma Aldrich, while diesel was obtained from a commercial diesel station in U.A.E. The smoke point apparatus is made up of a metallic cylindrical fuel reservoir (length: $10.9 \mathrm{~cm}$, internal diameter: $2.125 \mathrm{~cm}$ ) with a provision for air vent, a wick tube with a cotton wick of diameter $4.5 \mathrm{~mm}$ and a length of $125 \mathrm{~mm}$, a lamp body, and a stand that hold the burner fitted with a chimney of $13 \mathrm{~cm}$ height. An adjustable glass window is mounted in front of it to assist in the flame height measurement by a vertical scale fixed behind the flame. The cylindrical lamp body has a diameter of $81 \mathrm{~mm}$, which surrounds the burner and protects the flame from the environmental disturbances. A screw mechanism allows the flame height to be varied by lowering or raising the fuel reservoir. In order to collect soot from the tip of each fuel flame of $27 \mathrm{~mm}$ height, a filter assembly (from Sierra Instruments, USA), with a vacuum pump provision, was mounted over the chimney. The $70 \mathrm{~mm}$ diameter, borosilicate microfiber filters, strengthened with woven glass (TX40H120WW, Pall Filters, USA), was used to collect soot samples from the flames of all the tested fuels. The collected soot samples (approx. $20 \mathrm{mg}$ ) were then dried in a tube furnace (heating rate of $20^{\circ} \mathrm{C} / \mathrm{min}$ up to a temperature of $400{ }^{\circ} \mathrm{C}$ ) under $\mathrm{N}_{2}$ flow to remove water vapour and any loosely-bound hydrocarbons.

These samples were then subjected to chemical and morphological characterization. The nanostructural features of soot were found using FEI Tecnai G20 scanning HRTEM operated at $200 \mathrm{kV}$ with $0.24 \mathrm{~nm}$ point resolution, equipped with an energy-filtered camera. Soot samples were ultra-sonicated in ethanol for $10 \mathrm{~min}$ to disperse soot and a drop of this solution was applied to a lacey carbon-coated, 400 mesh copper grid followed by drying under an infrared lamp. The electron energy loss spectra (EELS) were obtained using Gatan Image Filter in the TEM mode with the energy resolution of $1 \mathrm{eV}$, and the spectra were recorded at a dispersion of $5 \mathrm{eV}$ per channel. For the oxidation of soot particles, a thermogravimetric 
analyzer (TGA, NETZSCH STA 409PC-LUXX) was used. The dried soot samples were heated in air from 200 to $800{ }^{\circ} \mathrm{C}$ at the heating rates of $1,3,5$, and $7{ }^{\circ} \mathrm{C}$ min-1. The elemental composition of soot samples was analysed by surface coating the particles with $\mathrm{Pd} / \mathrm{Au}$ for improved conductivity in a SEM-Carl Zeiss (JSM-5800LV) coupled with Ametex EDX PV6500 system. The quantitative information on the nanocrystallites present in soot were calculated from the XRD patterns found using Panalytical Empyrean powder X-ray diffractometer with $\mathrm{Cu}-\mathrm{K} \alpha$ radiation $(1.54 \AA$, $40 \mathrm{kV}, 40 \mathrm{~mA})$. The scan range was $10-80^{\circ}$ with the scan step size of $0.02^{\circ}$ and the scan speed of $10 \mathrm{~s} / \mathrm{step}$. The structural disorder in soot samples were further analysed using Raman spectrometer (Witech Alpha 300 RAS) equipped with $515 \mathrm{~nm}$ laser source and a dual purpose 50x objective lens.

\section{Results and Discussion}

\subsection{Smoke point, threshold sooting index, and fuel consumption rate}

The smoke points of diesel (D), camphor oil (CO), camphor oil-diesel blend (COD), and camphor solid-diesel blend (CD), as a function of blending percentage were measured by observing the flame height at which the sooting wings appear on both sides of the flame [23]. The comparative analysis of the variation in smoke point is presented in Figure 1a with a relative error of $\pm 1 \mathrm{~mm}$. It is observed that the blending of a small percentage of camphor oil to diesel results in the enhancement of the smoke point that increased from 19 for pure diesel to 23.3 and $21.3 \mathrm{~mm}$ for $10 \%$ camphor oil//90\% diesel (10\% COD) and 15\% camphor oil//85\% diesel (15\% COD), respectively. The further increase in the blending percentage of camphor oil resulted in a gradual decrease in the smoke point enhancing the sooting tendency of the blend. When pure camphor oil was tested, a smoke point of $13.7 \pm 1 \mathrm{~mm}$ was measured, which is significantly below the smoke point of pure diesel. In order to further investigate the cause of such a significant decrease in the smoke point at higher camphor oil-diesel blending ratios, the smoke point measurements were performed by blending pure camphor solid with diesel, as it is soluble in diesel up to a saturation limit of $20 \%$. This provided a way to eliminate the effect of secondary constituents present in the camphor oil and understand the sole influence of camphor on the sooting tendency of diesel. As seen in Figure 1a, the blending of camphor solid increases the smoke point of diesel to $22.3( \pm 1)$ with a small blending percentage of up to $5 \%$, possibly due to the presence of tricyclic structure with oxygen atom in the camphor molecule that could enhance the fuel radical formation rate, leading to improved fuel oxidation and reduced soot formation $[44,45]$. The smoke point falls drastically with the further increase in 
camphor content in diesel, consistent with the trend obtained in the case of higher blending percentage of camphor oil in diesel.

Since the smoke point is an instrument-dependent quantity, we further calculated an instrument-independent parameter, threshold sooting index (TSI), which is expressed as: TSI= $a(M W / S P)+b$, where $S P=$ smoke point, $M W=$ molecular weight of the fuel and, $a=3.76$ and $b=-3.75$ are instrumental constants determined using standard fuels with known TSI values [23]. The calculated TSI values for diesel (D), camphor oil (CO), 5\% camphor solid/95\% diesel blend (5\% CD) and 10\% COD are presented in Figure 1b. It is evident that both 5\% CD and $10 \%$ COD blends are effective in reducing the sooting tendency of diesel.
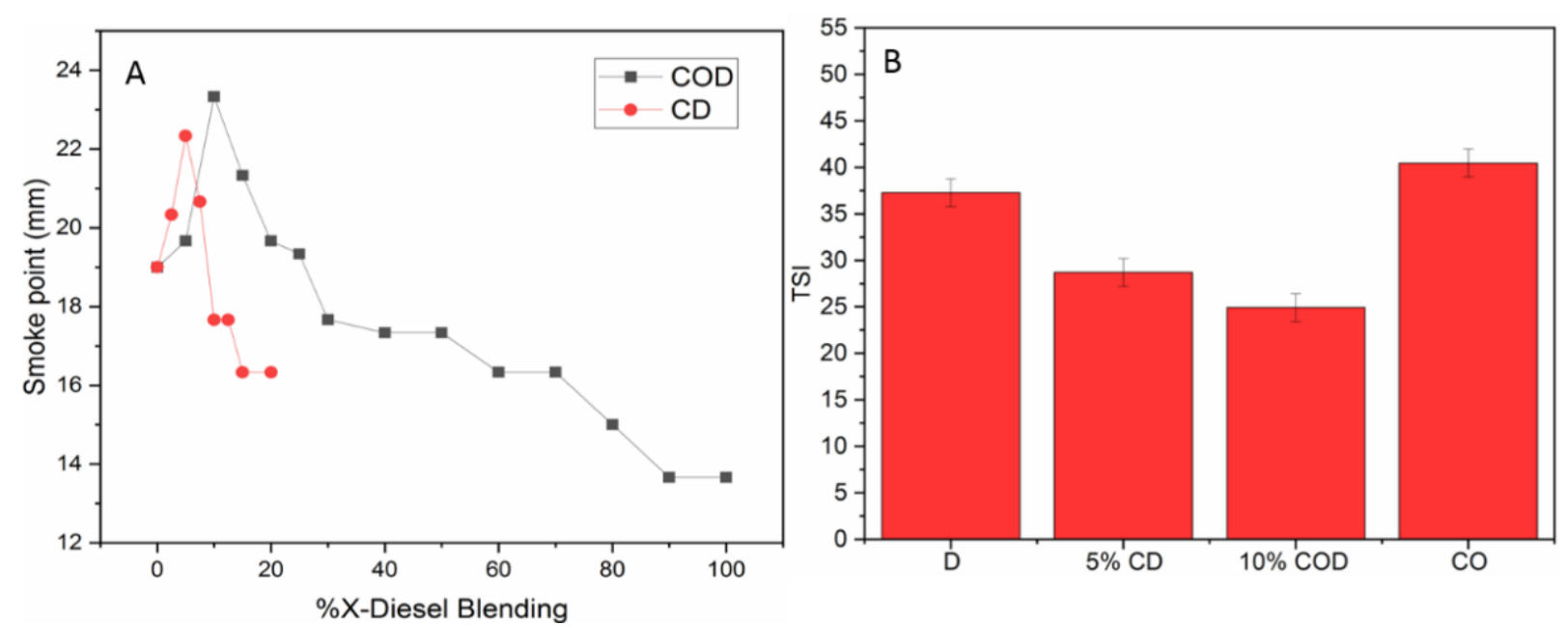

Figure 1: (a) Variation in smoke point $(S P$ error $= \pm 1 \mathrm{~mm})$ with different blending percentages of camphor oil and camphor solid with diesel. (b) Calculated TSI for pure diesel (D), 5\% CD, $10 \%$ COD, and pure camphor oil (CO).

It is interesting to note that the relative decrease in the smoke point with increasing percentage of camphor solid in diesel is significantly more drastic as compared to that of COD blends. This could be attributed to the presence of a relatively greater amount of camphor in CD as compared to $\mathrm{COD}$ at the same blending percentage. The high sooting tendencies of pure camphor/camphor oil and of the blends containing their high percentages are explained as follows. It has been reported that, at low temperatures, camphor can undergo secondary reactions such as oxidative dimerization with its in-situ generated enoxy radical to form exo,exo' or endo,endo'-3,3'-bicamphor, or its corresponding biisoborneol derivatives [46,47]. Although flame temperature is significantly high ( $>800 \mathrm{o}$ ), many alkoxy and peroxy radicals are formed in flames via fuel pyrolysis and partial oxidation. Under low oxygen environments, 
such initially formed alkoxy radicals may initiate dimeric nucleation similar to the case discussed above, and could enhance the cyclization reactions to form PAH-like structures. Subsequently, this may lead to the enhancement in soot formation with the increase in camphor blending percentage in diesel. When a high percentage of camphor oil is blended with diesel, the decrease in smoke point is relatively slower, which could be attributed to i) relatively lower percentage of camphor content (i.e. $\sim 50 \%$ in pure oil) in the blend, and also ii) the presence of other oxygenated compounds such as linalool $(\sim 23 \%)$ and 1,8-cineol $(\sim 11.5 \%)$ that together increases the total oxygen content of the fuel to decrease sooting tendency.

For a given fuel, the change in the fuel mass flow rate in a flame can also affect significantly the mass production and physicochemical properties of soot. The fuel mass flow rate in diffusion flames is a simplified representation of the increase in the engine load that also results in an increased injection of fuel to the cylinder. In this study, the fuel mass flow rate was measured to ensure that the experimental results mimic diesel engine conditions, where soot emissions from various fuels are quantified at a constant fuel mass flow rate [48]. In our experiments, the fuel mass flow rates for the above fuels and their blends were calculated by continuously monitoring the weight loss of the fuel in the burner as a function of burning time for the fixed flame heights of 10,20, and $30 \mathrm{~mm}$. For each flame height, the weight loss of the fuel was plotted versus time (where, an outstanding linearity was obtained), and the slope of the plot depicted the fuel mass flow rate. A plot of fuel mass flow rate versus flame height was almost linear ( $\left.\mathrm{R}_{2}=0.98\right)$, as shown in Figure SF1 (supplementary data file). It was found to be largely constant at a fixed flame height for all the fuels. The largest dissimilarity between the fuel mass flow rates at a fixed flame height is $7 \%$, and in most of the cases it is below $4 \%$. These small differences could mainly arrive from the uncertainly of $\pm 1 \mathrm{~mm}$ in flame height measurement in the smoke point apparatus. Even when a flame height is fixed, some fluctuation in the diffusion flame is experimentally seen that slightly changes the flow rate (as shown by the error bars in the plot). Thus, while it is theoretically viable to fix fuel mass flow rate and flame height, small fluctuations in the flame are always present. Since the differences are very small, it is justified to consider the fuel mass flow rates of different fuels to be same at a given flame height [49].

Since the measured average smoke points of D, 5\% CD, and 10\% COD fuels were 19, 23, and $24( \pm 1) \mathrm{mm}$, respectively, soots from all these fuels were collected at a fixed flame height of $27 \mathrm{~mm}$ (that was above the smoke points of all the tested fuels). The effect of camphor oil and camphor solid blending with diesel on the kinetics of their soot oxidation with $\mathrm{O}_{2}$ was further 
investigated using thermogravimetric analysis, and their results are presented in the next section.

261

\subsection{Thermogravimetric analysis}

263 Soot oxidation in engines and in DPFs is strongly dependent on its reactivity with $\mathrm{O}_{2}$. 264 Therefore, thermogravimetric analysis in air have been performed to investigate the kinetics of $265 \mathrm{O}_{2}$-induced soot oxidation. The overall oxidation process can be generalised to produce either $266 \mathrm{CO}(\mathrm{g})$ or $\mathrm{CO}_{2}(\mathrm{~g})$ and other side products, without accounting for large complex reaction 267 models. A typical soot oxidation in TGA involved heating known quantities of soot samples derived from D, 5\% CD, and 10\% COD blended fuels in air from 200-800 oC at different heating rates of $1,3,5$, and $7 \mathrm{oC} / \mathrm{min}$. The typical variation in soot conversion $(\alpha)$ and conversion rate $(\mathrm{d} \alpha / \mathrm{dt})$ at varying heating rates in the case of soot obtained from $10 \%$ COD is presented in Figure 2a and 2b, respectively, while those for D and 5\% CD soot can be found in Figure SF2 in the supplementary data file. The soot conversion $(\alpha)$ is defined as $\alpha=$ (MoМт)/(Mo-ML) with Mo being the initial soot mass, Mr being the mass of partially oxidized soot at temperature $\mathrm{T}$, and $\mathrm{ML}$ being the leftover mass (mostly ash). The reactivity of soot at different conversion levels is evaluated by calculating the activation energies for soot oxidation using Friedman method [50,51], wherein the rate of soot conversion $\left(\frac{d \alpha}{d t}\right)$ is equated to soot conversion $(\alpha)$ by Equation E1. 

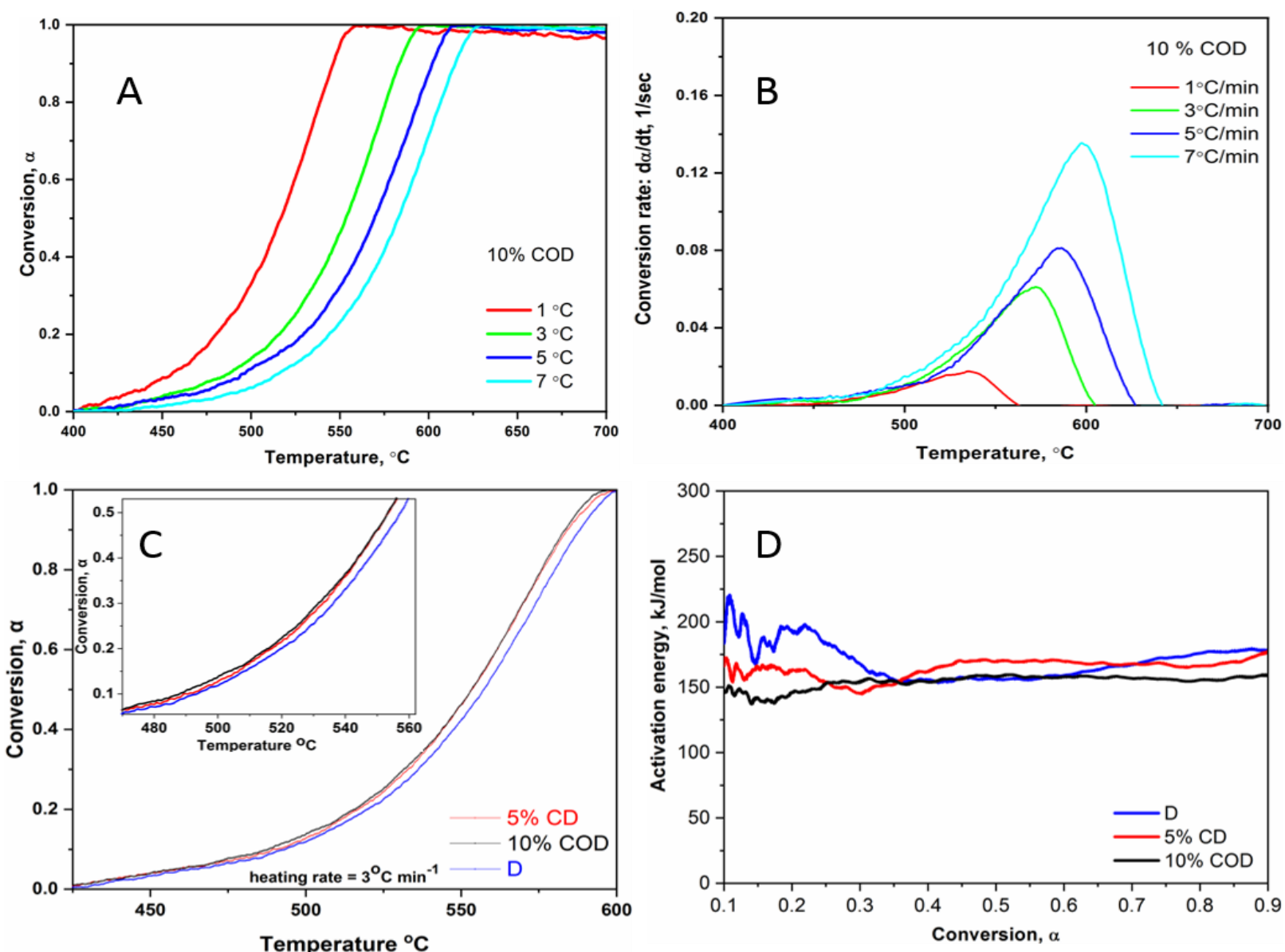

Figure 2: (a) soot conversion, $\alpha$, and (b) soot conversion rate (da/dt) measured in air at different heating rates. Comparative analysis of (c) soot conversion, $\alpha$ measured at a fixed

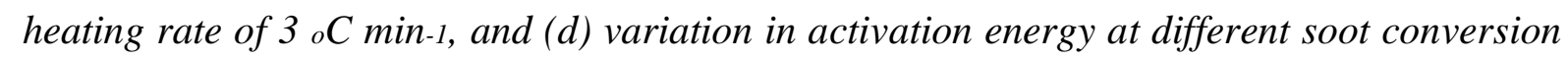
levels measured in case of soots obtained from 5\% CD, $10 \%$ COD and D.

$$
\frac{d \alpha}{d t}=k(T) f(\alpha)
$$

In the above equation, $k(T)$ is the rate constant ( $\mathrm{s}-1)$ of $\mathrm{O}_{2}$-induced soot oxidation, expressed by

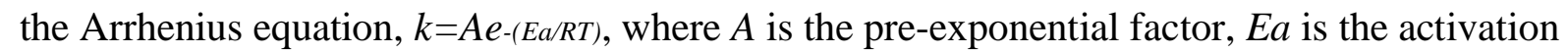
energy of soot oxidation, and $T$ is the temperature [52]. The term, $f(\alpha)$ describes the reaction model or the conversion function. Since the concentration of $\mathrm{O}_{2}$ is maintained constant throughout the TGA experiment, its expression in rate equation is omitted. For further details about the procedure and activation energy calculation, please refer to [25,53].

The calculated activation energies at different conversion levels and temperatures are presented in Figure 2d. It can be seen that, at low conversion level (i.e. $\alpha=0.1$ ), the activation energies of the three soot samples differ significantly. The 10\% COD soot has the lowest initial activation energy of $150 \mathrm{~kJ} / \mathrm{mol}$, followed by $175 \mathrm{~kJ} / \mathrm{mol}$ for $5 \%$ CD soot, while the diesel soot had the highest initial activation energy of $220 \mathrm{~kJ} / \mathrm{mol}$. The higher oxygen content in soot 
increases the evaporation rate of loosely bound/volatile substances in soot and induces internal oxidation of the soot structure [54]. Therefore, the observed increase in the activation energy of soot oxidation could be attributed to the relative decrease in the amount of oxygen/oxygen functionalities on soot surface [54], in the order of 10\% COD > 5\% CD > D (which has been confirmed through elemental analysis, as shown later). The observed trend of activation energy is maintained up to a conversion level of $25 \%$, beyond which, a reversal in activation energy trend between 5\% CD and D soots is observed. The calculated value of the average activation energies at all conversion levels were 154, 165 and $170 \mathrm{~kJ} / \mathrm{mol}$ for $10 \% \mathrm{COD}, 5 \% \mathrm{CD}$, and D soots, respectively.

The activation energies for soot and carbon black are found in the range of 130-200 kJ/mol in the literature [55]. For commonly used palm oil-derived biodiesel blended fuels, which contain two oxygen atoms per molecule of methyl ester, (i.e., a high concentration of fuel-bound oxygen), the activation energy for soot oxidation is reported to be relatively lower in the range of $100-150 \mathrm{~kJ} / \mathrm{mol}[54,56]$. Such oxygen-rich fuel blends are reported to produce soots with high $\mathrm{O} / \mathrm{C}$ ratio, and the subsequent decomposition of strongly bound oxygenated functional groups on soot to $\mathrm{CO}$ and $\mathrm{CO}_{2}$ (especially above $400 \mathrm{o}$ ) is known to enhance the soot oxidation rate $[57,58]$. The higher oxygen content in soot also leads to a better exposure of carbon atoms to ambient oxidants further accelerating the oxidation rate [59]. Since the concentration of fuel bound oxygen in camphor solid/camphor oil is relatively lower than biodiesel, the trend of average activation energies measured in this study for the 5\% CD and 10\% COD soot fall very much within the above expected range. However, it is to be noted that, some literature reports also have obtained contradictory results, wherein the soot oxidation rates have been found to be poorly dependent on the fuel-bound oxygen content/or the oxygen functionalities bonded to the soot surface [15]. Instead, the structural disorders in soot nano/microstructures have been reported to have much greater influence on the reactivity. The reversal in trend observed at the higher conversion levels in the present study, therefore, could have been influenced by a combination of parameters such as structural disorders, a larger amorphous content, a greater percentage of curvature in the lattice fringes, a decrease in the ratio of the number of edge to basal $\mathrm{C}$ atoms, and a higher amount of aliphatic hydrocarbons present in soot [60-62]. Therefore, all the soot samples were subjected to EDX elemental analysis, XRD, HRTEM, Raman, and EELS measurements to obtain more information about the average O/C ratio, microstructural disorder, PAH stack size, shape, and $\sigma / \pi$ bonding characteristics of soot, which will be discussed in the subsequent sections. 


\subsection{Elemental Analysis}

To get an estimate of the relative distribution of carbon and oxygen atoms on the soot surface produced from D, 5\% CD and 10\% COD blended fuels, all soot samples were subjected to Energy Dispersive X-ray Spectroscopic (EDX) analysis using Ametex EDX PV6500 system, and the data was processed using eZAF Smart Quant analyser. The weight and the atomic percentages estimated for $\mathrm{C}$ and $\mathrm{O}$ ( $\mathrm{H}$ atoms are not detected with this method) at three different portions of each soot sample are presented as inset in Figure 3.
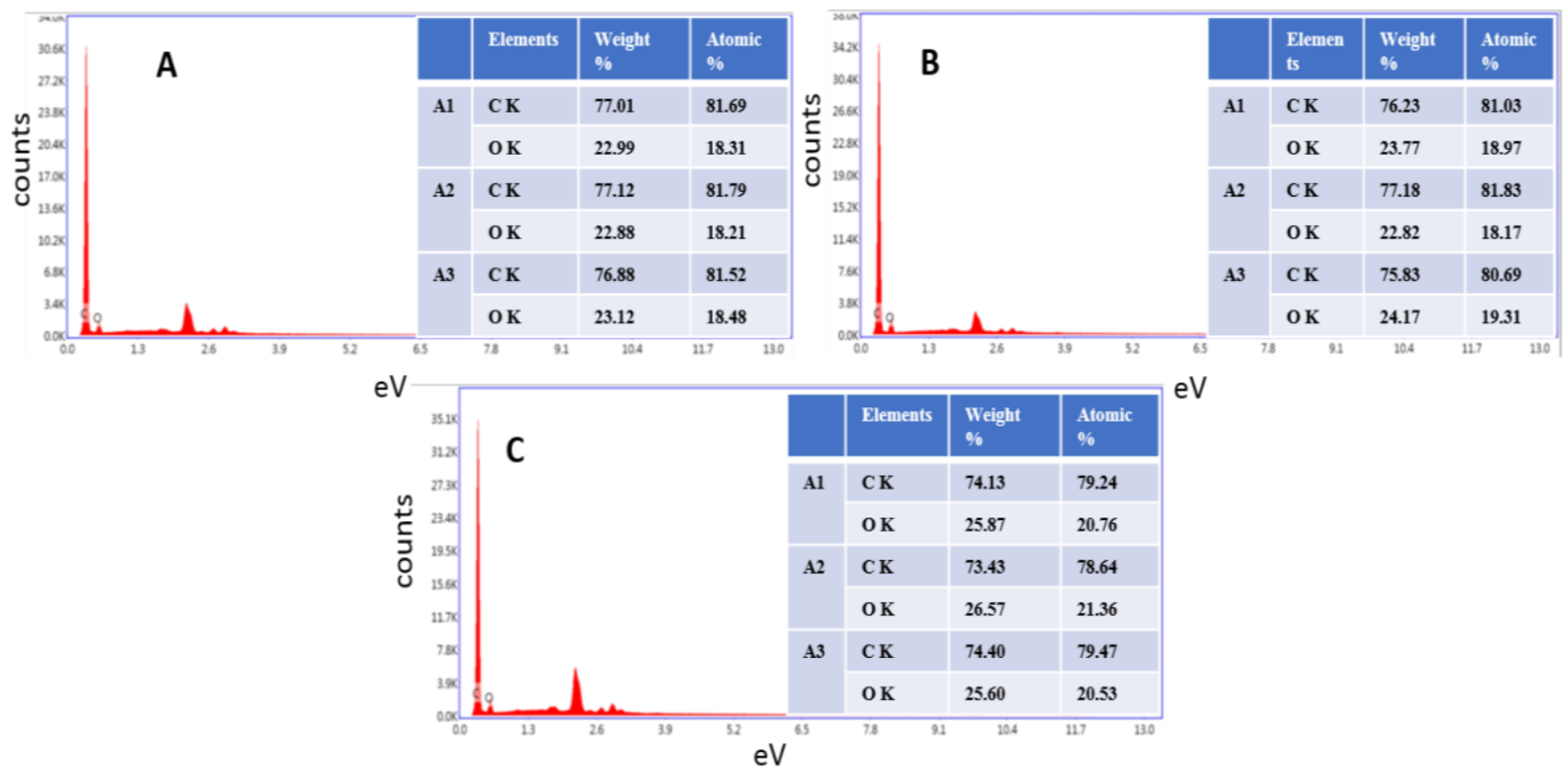

Figure 3: EDX data of soot obtained from (a) D, (b) 5\% CD, and (c) $10 \% \mathrm{COD}$, wherein Al, $A_{2}$ and $A 3$ represent elemental composition of three different regions of each soot sample.

Since element-specific calibration of the instrument was not performed, the results obtained are used as a qualitative indicator, but can be utilized to compare average $\mathrm{O} / \mathrm{C}$ ratio of the three soot samples, as reported in [63]. As evident from Figure 3, the average O/C ratio increased from $0.224( \pm 0.002)$ for D soot to $0.239( \pm 0.004)$ and $0.264( \pm 003)$ for $5 \% \mathrm{CD}$ and $10 \% \mathrm{COD}$ soots, respectively. This indicates that the presence of higher amount of oxygen in the $10 \%$ COD blended fuel also induces relatively higher concentration of oxygen functionality in soot as compared to $5 \% \mathrm{CD}$ and $\mathrm{D}$, which correlates well with the initial oxidative reactivity of soot. Nonetheless, this could well be a coincidence and other structural disorders may have a significant role to play in inducing soot reactivity, as presented in the next section. 


\subsection{High Resolution Transmission Electron Microscopy (HRTEM)}

Figure 4 represents the typical HRTEM images for D, 5\% CD, and 10\% COD soots at different resolutions of 5, 10 and $20 \mathrm{~nm}$. It is evident from Figure 4(C,F,I) that all the soot samples are composed of agglomerated near-spherical particles, which are also called primary soot particles. These primary particles appear to be connected/fused to neighbouring particles due to the sintering effect. Each primary particle is composed of core-shell-like structure (see images $A, D, G)$, where the core is composed of curved fringes of short length and the shell is composed of long range fringes, concentrically arranged along the periphery [6,64]. The short core fringes represent a high degree of structural disorder, which is due to the internal oxidation of soot particles, as they move up in the flame [6,64].

The comparative analysis of the average diameter of the primary particles of the three samples was performed using the Gatan software, where around 30-40 particles were identified from different HRTEM images at $20 \mathrm{~nm}$ resolution. The results are shown in Figure 5. It is evident that the average particle diameter is largest in the case of diesel soot (around $52 \mathrm{~nm}$ ) as compared to the average diameters of $40 \mathrm{~nm}$ and $37 \mathrm{~nm}$ for $5 \% \mathrm{CD}$ and 10\% COD soots, respectively. The similarity in the particle diameters of 5\% CD and $10 \% \mathrm{COD}$ soots indicates the role of camphor molecule in reducing the growth rate of soot nuclei, which is in agreement with the TSI measurements. It can be clearly seen in subfigure $G$ that the fringe structure in the case of $10 \%$ COD soot is highly disordered with the existence of multiple nano core-shell structures within a single primary particle as compared to the other two soot samples.

The further quantitative analysis of fringe length and tortuosity was done using an in-house Matlab code (developed based on the algorithms of $[65,66]$ ), wherein the first step involves the negative transformation of the HRTEM image that converts it to grayscale. The multiple regions of interest (ROI) are then selected. On these ROI, several operations such as Gaussian filter, histogram equalization, and top-hat transformation are performed. In order to remove branches from fringes, firstly the all branch points are identified in the resulting image using the built-in Matlab "branchpoints" morphological operation. Starting from each of these branch points, the length of the fringe is noted in all directions. Once the smallest branch is identified, the connection to this branch is broken by setting the first pixel to this branch to zero. The newly constructed processed fringe structure is presented in Figure $6(\mathrm{~A}, \mathrm{~B}, \mathrm{C})$ for diesel, $5 \%$ $\mathrm{CD}$, and $10 \% \mathrm{COD}$ soot samples, respectively. The quantitative information about the fringe lengths and fringe curvature (i.e. tortuosity index) has been obtained by analysing all the fringe patterns in the above processed images, and the result obtained are presented as subfigures A1A2, B1-B2, and C1-C2 in Figure 6 and Table 1. 


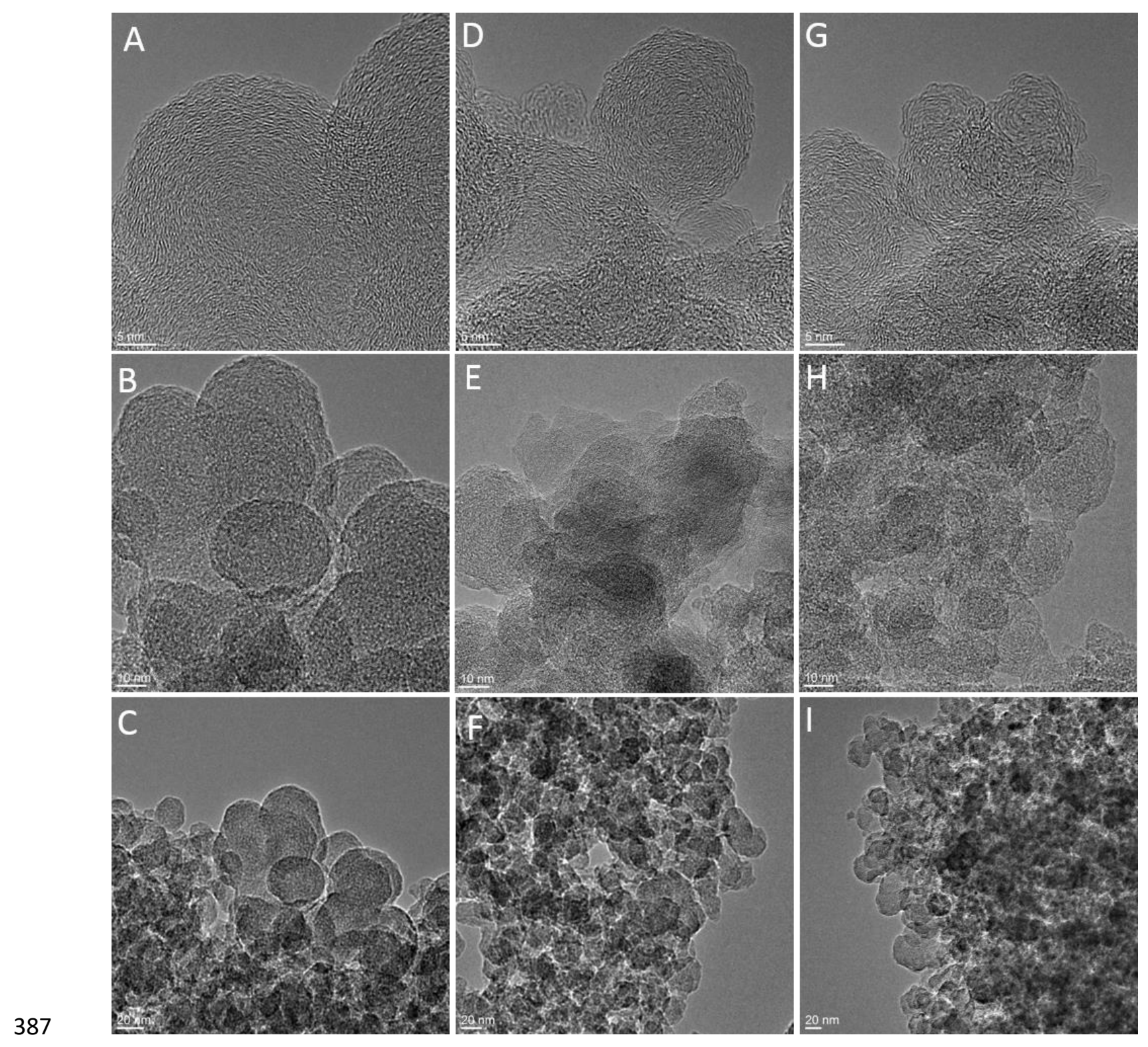

388 Figure 4: HRTEM micrographs of (A-C) Diesel, (D-F) 5\% CD, and (G-I) 10\% COD soots at 389 different resolutions of 5,10 and $20 \mathrm{~nm}$.

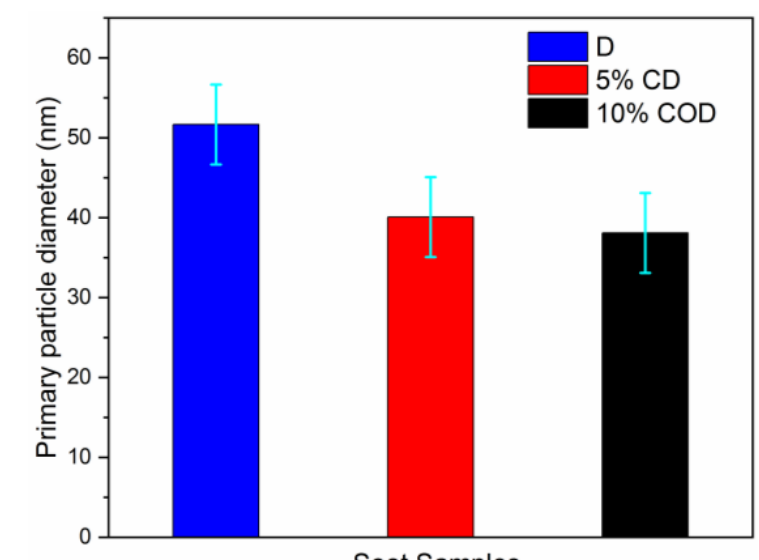

Soot Samples

391 Figure 5: Average primary particle diameter for Diesel, 5\% CD and 10\% COD soot samples 392 obtained using the HRTEM micrographs at $20 \mathrm{~nm}$ resolution. 

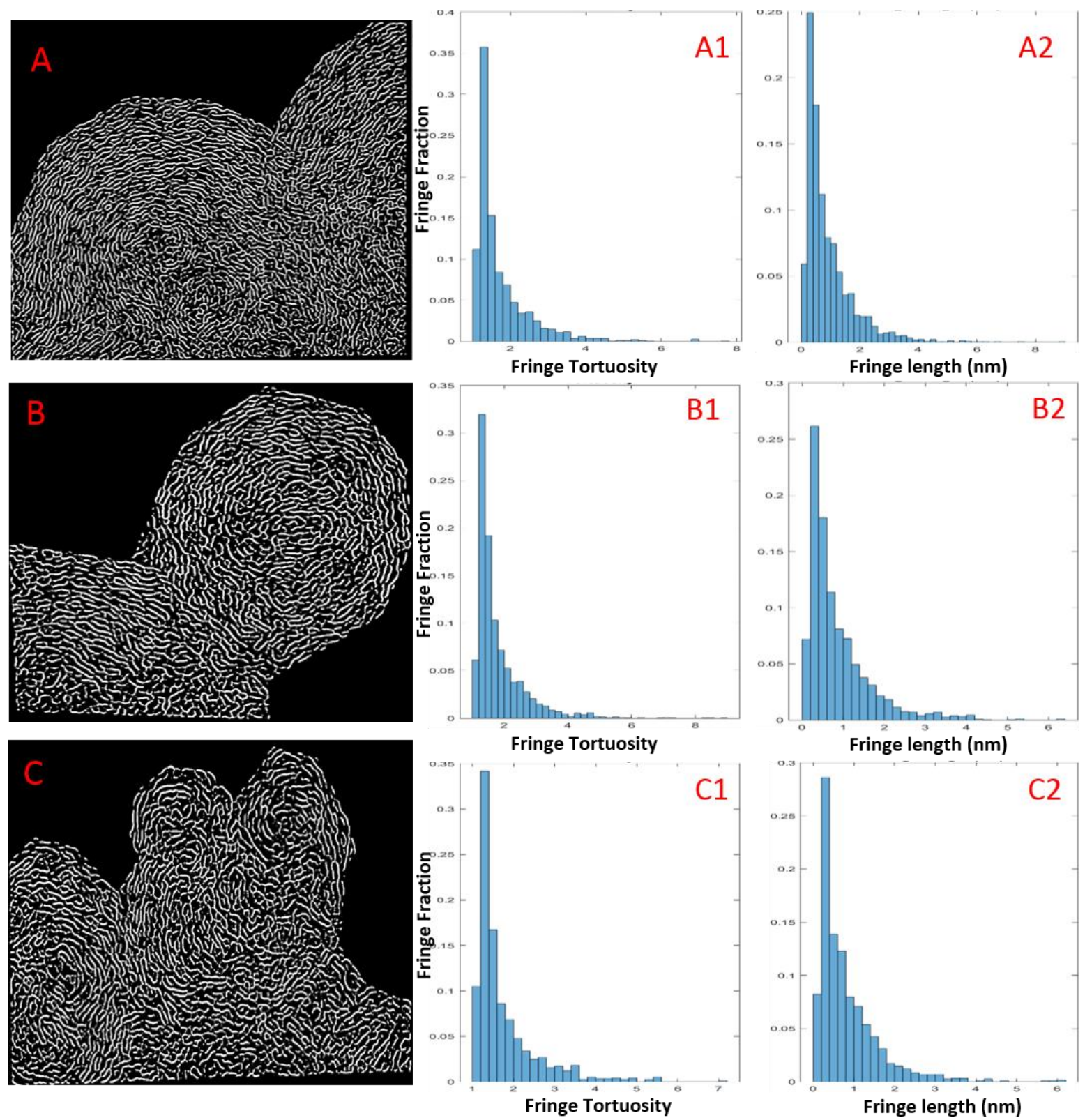

Figure 6: Processed fringe nanostructure, fringe tortuosity and fringe length distribution in ( $i)$ diesel (A, $A 1, A 2),(i i) 5 \% C D(B, B 1, B 2)$, and (iii) $10 \% C O D(C, C 1, C 2)$ soots, respectively.

Table 1: Mean fringe length and mean fringe tortuosity of D, 5\% CD and 10\% COD soots.

\begin{tabular}{|c|c|c|}
\hline Sample & Mean Fringe Length $(\mathbf{n m})$ & Mean Fringe Tortuosity \\
\hline $\boldsymbol{D}$ & 0.92 & 1.73 \\
\hline $\mathbf{5 \%}$ CD & 0.86 & 1.82 \\
\hline $\mathbf{1 0 \%}$ COD & 0.83 & 1.85 \\
\hline
\end{tabular}

399 It is evident from Table 1 that diesel soot particles have the largest mean fringe length of 0.92 $400 \mathrm{~nm}$, which decreases to $0.86 \mathrm{~nm}$ and $0.83 \mathrm{~nm}$ in the cases of $5 \% \mathrm{CD}$ and $10 \% \mathrm{COD}$, 
401

402

403

404

405

406

407

408

409

410

411

412

413

414

415

416

417

418

419

420

421

422

423

424

425

426

427

428

429

430

431

432

25

26

respectively. Moreover, the analysis of the tortuosity index suggests that the short fringes in $10 \%$ COD soot also have the highest curvature (1.86) compared to diesel soot (1.73). Therefore, the shorter fringe length and the largely curved fringes together make the $5 \% \mathrm{CD}$ and $10 \%$ COD soots highly disordered or amorphous, and hence, more prone to oxidation, as desired for the fast regeneration of DPF filters. The disorder in the crystal structure of these soot samples is further analysed using XRD and Raman spectroscopy.

\subsection{X-Ray Diffraction analysis}

The X-ray diffraction patterns of D, 5\% CD, and 10\% COD soots are presented in Figure 7, and the quantitative information about the PAH stacks is determined from their analyses. All the three soot samples displayed two typical distinctive peaks at $2 \theta$ values of around 24.5 o and 44 o, respectively. A third minor peak around 80 o of weaker intensity is observed due to the (110) plane, and is an indicator of the presence of non-graphitic carbon in the soot samples [67]. The observed broad peaks (24.5o and 44o) are indicative of the random alignment of nanocrystallites into a largely amorphous graphitic structure in soot. The peak at $2 \theta$ value of 24.5 o is assigned to the (002) plane, and it inculcates the information about the thickness of the PAH stack and the PAH interlayer spacing in it $[25,68]$. The peak at $2 \theta$ value of $44_{\mathrm{o}}$ is assigned to the (100) plane and is indicative of the average PAH size in a soot sample. Further analysis of these peaks were carried out to obtain the structural parameters associated with the nanocrystallites present in soot samples, such as (i) PAH interlayer spacing (d002) as per Bragg's law (see equation E2), (ii) the nano-crystallite height (Lc), which gives the thickness of the PAH stack, using Scherrer formula (see Equation E3), and (iii) the nano-crystallite width (La) which provides the average PAH stack size using Equation E4 [69].

$$
\begin{aligned}
& d_{002}=\frac{\lambda}{2 \sin \theta_{002}} \\
& L_{c}=\frac{0.9 \lambda}{B_{002} \cos \theta_{002}} \\
& L_{a}=\frac{1.84 \lambda}{B_{100} \cos \theta_{100}}
\end{aligned}
$$

In the above equations, $\lambda$ is the wavelength of $\mathrm{X}$-ray $(1.54 \AA$ for $\mathrm{Cu}-\mathrm{K} \alpha), \theta_{002}$ and $\theta 001$ are the Braggs angles, and B002 and B100 are the full width at half maximum (FWHM) for the two peaks, respectively. The Braggs angles and the FWHM were obtained via Gaussian fitting of the respective peaks using Matlab software. The obtained values are listed in Table 2. 


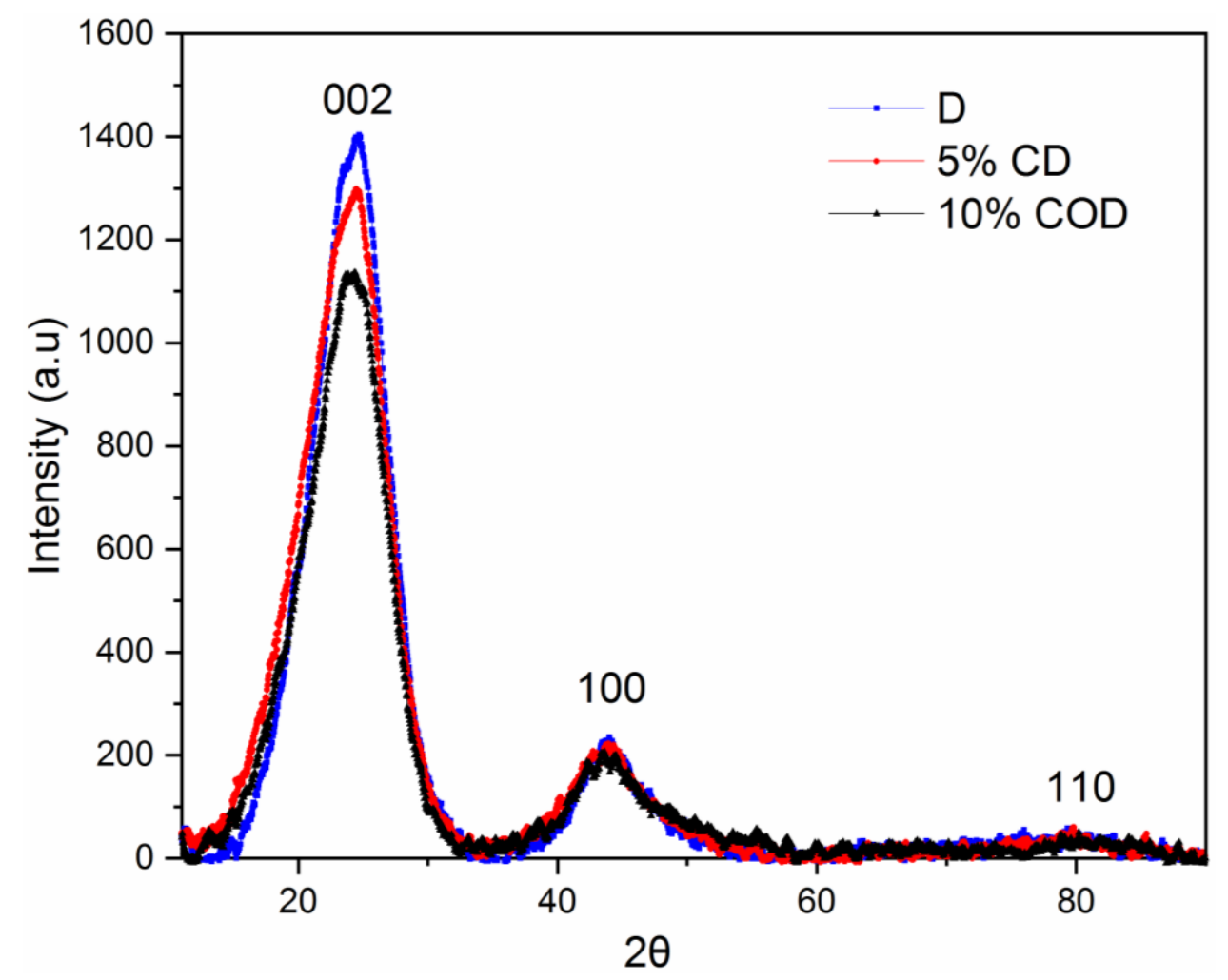

Figure 7: XRD pattern of soot samples derived from 5, 5\% CD and 10\% COD.

Table 2: Crystallite parameters of soot samples obtained from XRD analysis

\begin{tabular}{|c|c|c|c|c|}
\hline Sample & $\boldsymbol{d o 0 2}(\boldsymbol{\AA})$ & $\boldsymbol{L} \boldsymbol{c}(\boldsymbol{\AA})$ & $\boldsymbol{L} \boldsymbol{a}(\boldsymbol{\AA})$ & $\boldsymbol{L} \boldsymbol{c} \mathbf{d o 0 2}$ \\
\hline $\boldsymbol{D}$ & 3.62 & 12.00 & 29.32 & 3.31 \\
\hline $\mathbf{5 \%} \boldsymbol{C D}$ & 3.63 & 11.78 & 27.35 & 3.24 \\
\hline $\mathbf{1 0 \%} \boldsymbol{C O D}$ & 3.68 & 11.12 & 26.11 & 3.02 \\
\hline
\end{tabular}

437

The calculated values of d002 for all three soot samples were in close range. The substantially greater values of d002 in soot compared to graphite (3.354 $\AA$ ) indicates that all soot samples have a highly disordered structure. Moreover, the slightly greater d002 values in 10\% COD soot as compared to the other two soot samples infer relatively weaker bonding interactions between the PAH stacks, which further enhances their oxidation rate in TGA experiments [70]. The estimated Lc value of $10 \%$ COD soot (11.12 $\AA$ ) was found to be the lowest as compared to the other two soots, while the Lc/d002 ratio, which is a measure of the number of graphene layers in a coherent graphitic stack, decreases in the order, $\mathrm{D}>5 \% \mathrm{CD}>10 \% \mathrm{COD}$. This suggests that the oxidation of camphor partially alters the oxidation mechanism of diesel in a way that favours face to face association over edge to edge coalescence of the graphene layers, as suggested by Hurt et al. [71]. The La values decrease substantially in the order D>5\% CD>10\% COD. The 
low La value is an indicator of the small size of the PAH stack. Moreover, it has been well established that the smaller size of the PAH stack is associated with an increase in the edge carbon atoms as compared to the basal carbon atoms. Since the edge carbon atoms in the graphene sheet are more reactive compared to the basal carbon atoms, soot obtained from $10 \%$ COD are more easily oxidized by $\mathrm{O}_{2}$ as compared to the other two soot samples [21].

\subsection{Raman Spectroscopic analysis}

The typical convoluted Raman bands, as observed in the first order region of 900-2000 cm-1 of the three soot samples, is presented in Figure 8. The broad band near $1350 \mathrm{~cm}-1$, called the D band, is associated with the disordered structure of soot particles. The G band, observed near $1590 \mathrm{~cm}-1$, is relatively sharper, but slightly shifted above the expected value of $1580 \mathrm{~cm}-1$ for graphitic structure, further suggesting the high degree of disorder in the soot structure [72,73]. The five-curve deconvolution model was used to analyse all the Raman spectra, wherein Voigt function was used to fit the raw experimental data, as suggested in [74]. The corresponding five peaks were labelled as D1 $=1345 \mathrm{~cm}-1, \mathrm{D} 2=1560 \mathrm{~cm}-1, \mathrm{D} 3=1445 \mathrm{~cm}-1, \mathrm{D} 4=1220 \mathrm{~cm}$ 1, and $\mathrm{G}=1590 \mathrm{~cm}-1$. The D2 band corresponds to lattice vibrations, while the D3 band signifies the presence of highly amorphous carbon in soot. The genesis of D4 band is less understood, and is believed to be a result of $\mathrm{C}-\mathrm{C}$ and $\mathrm{C}=\mathrm{C}$ vibrations in polyene-like structures [72]. The relative intensity of the $\mathrm{D}$ and $\mathrm{G}$ bands serves as an indicator of the magnitude of discontinuities and disorientation of the graphene layers present in soot [74]. Therefore, the ratio of $\mathrm{ID}_{\mathrm{D}} / \mathrm{I}_{\mathrm{G}}$ is obtained, and via an inverse relation, it is equated to the lattice width (La) using the Knight and White equation (E5), as suggested in [75]. The intensity of the D1 peak and a proportionality constant of 4.4 for the excitation wavelength of $515 \mathrm{~nm}$ is used, as suggested in $[75,76]$. The calculated values of ID1/IG and La are listed in Table 3.

$$
L_{a}=4.4\left(\frac{I_{D 1}}{I_{G}}\right)^{-1}
$$

In Table 3, the ID1/IG ratio increases and the corresponding value of La decreases on moving from D soot to $10 \% \mathrm{COD}$ soot. It is noted here that the calculated values of La are in close agreement with those obtained from XRD studies, which further confirms that the degree of lattice disorder increases due to the blending of camphor solid and camphor oil with diesel. Thus, both the XRD and the Raman studies very well compliment the TGA experiments, wherein the initial activation energy of soot oxidation by $\mathrm{O}_{2}$ was found to decrease due to the blending of $5 \%$ camphor solid and $10 \%$ camphor oil with diesel in the early stages of oxidation process. 

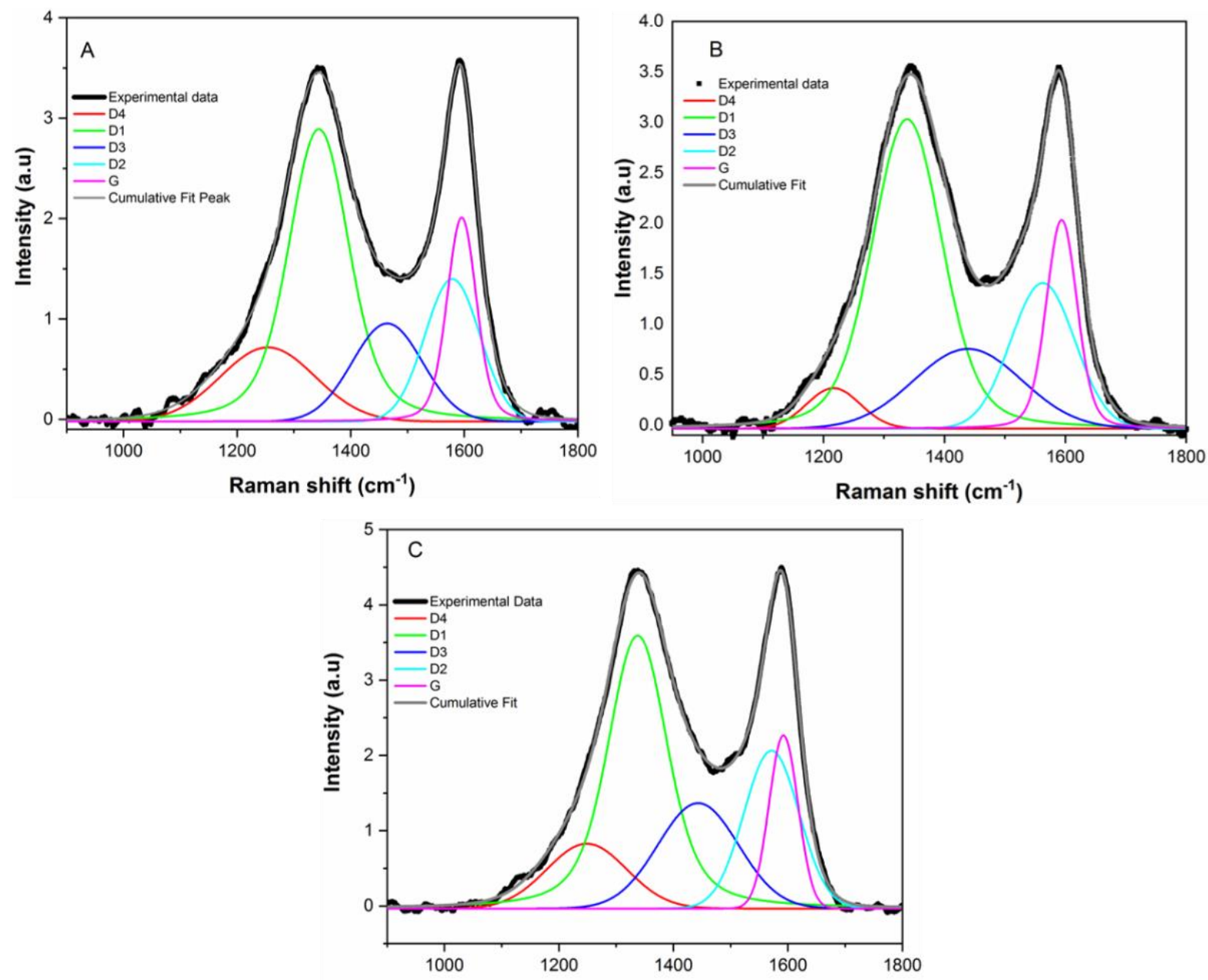

Raman shift $\left(\mathrm{cm}^{-1}\right)$

Figure 8: First order Raman spectra of A) Diesel, B) 5\% CD and C) 10\% COD soot samples.

Table 3: Structural parameters extracted from the Raman spectra of soot samples.

\begin{tabular}{|c|c|c|}
\hline Sample & IDI/IG & La \\
\hline $\boldsymbol{D}$ & 1.45 & 29.7 \\
\hline $\mathbf{5 \%} \boldsymbol{C D}$ & 1.50 & 28.6 \\
\hline $\mathbf{1 0 \%} \boldsymbol{C O D}$ & 1.59 & 26.8 \\
\hline
\end{tabular}

\subsection{Electron Energy Loss Spectroscopy (EELS)}

488 The EELS technique serves as a very effective tool in investigating the ordered/disordered graphitic characteristics and aliphatic/aromatic structural composition of the soot samples based on the quantitative estimation of the peak structures and the relative intensity ratio of $1 \mathrm{~s}$ to $\pi^{*}$ and $1 \mathrm{~s}$ to $\sigma^{*} \mathrm{~K}$ edge transitions that occur on the soot surface [67]. When the EELS spectra of the three soot samples, presented in Figure 9, are compared, significant differences in the $\pi^{*}(285 \mathrm{eV})$ and $\sigma^{*}(292 \mathrm{eV})$ peaks are observed. The $\pi^{*}$ peak, which indicates the $\mathrm{C}=\mathrm{C}$ 
bond character due to presence of aromatics, is often referred to as the graphite peak, while the $\sigma^{*}$ peak indicates the ordering of the graphitic layers [77]. Both the peaks are distinctly sharp and well developed in the case of diesel soot. However, the two peaks are relatively less developed and have broad hump-like structure in the case of soots collected from 5\% CD and $10 \%$ COD, confirming that these soots have highly disordered graphene layers (in agreement with the HRTEM, XRD, and Raman studies).

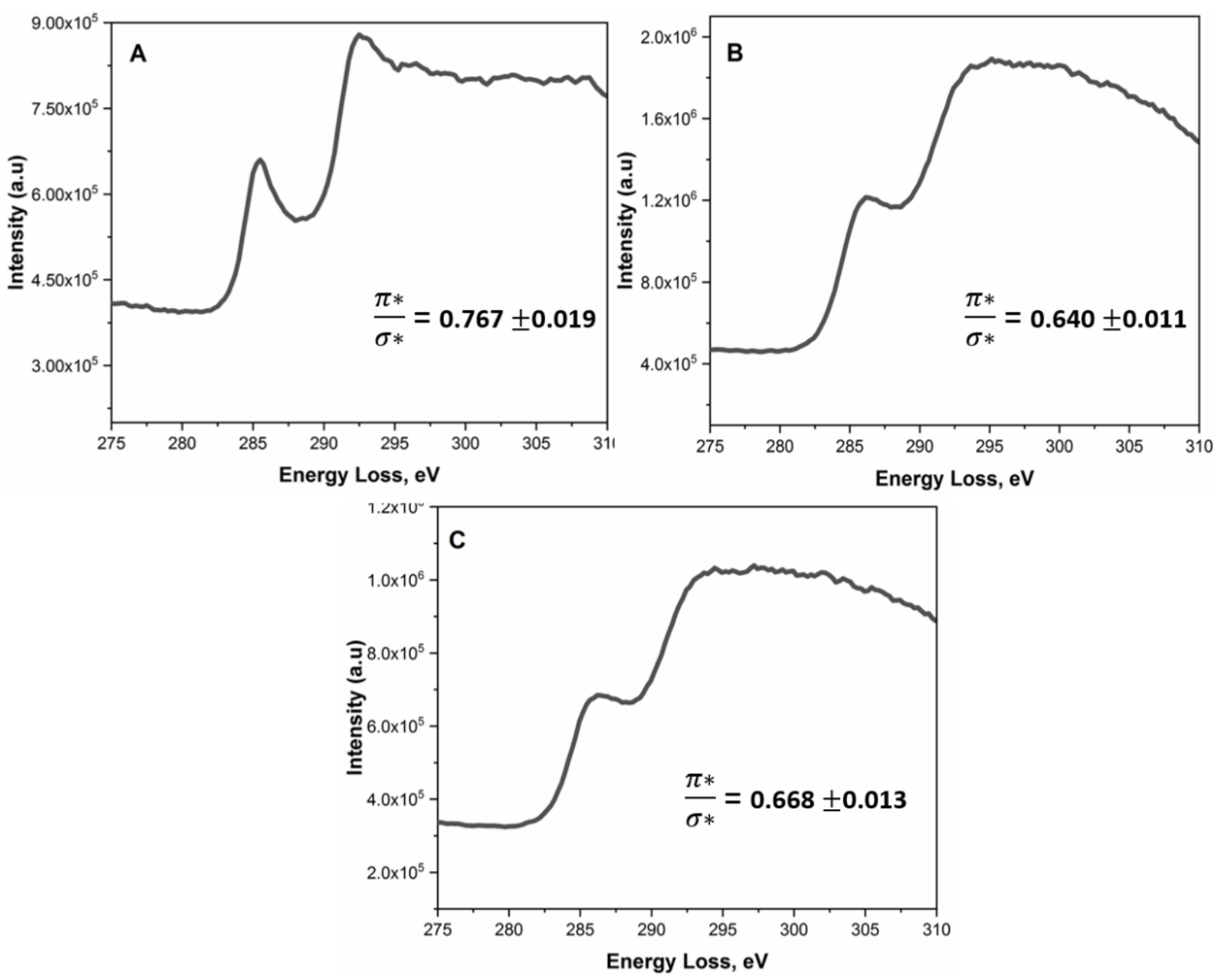

Figure 9: Electron energy loss spectra of A) Diesel, B) 5\% CD and C) 10\% COD soots.

The further analysis of the relative distribution of aromatics and aliphatics in soot is performed by calculating the $\pi^{*} / \sigma^{*}$ ratio using the EELS intensities of 285 and $292 \mathrm{eV}$ peaks. The low value of $\pi^{*} / \sigma^{*}$ ratio indicates high aliphatic content in soot [68]. The obtained values of 0.767 $( \pm 0.019), 0.640( \pm 0.011)$, and $0.668( \pm 0.013)$ in the cases of $\mathrm{D}, 5 \% \mathrm{CD}$ and $10 \%$ COD soots, respectively, confirm that the $5 \% \mathrm{CD}$ soot had the highest aliphatic content followed by $10 \%$ COD and D soots. It is well known that aliphatic compounds are oxidized at a faster rate than aromatics. This could explain the reversal in activation energy trend observed at the conversion level of $30 \%$ in TGA, wherein 5\% CD soot has the lowest activation energy. As the oxidation 
progresses to higher conversion levels, the lack of smaller PAH crystallites and the loss of oxygenated species followed by the graphitization of soot structure could have resulted in a further increase in the activation energy for the oxidation of 5\% CD soot. Since, the diesel soot already possesses relatively higher degree of graphitic character (as confirmed through EELS studies), the relative change in the graphitic character at higher conversion levels during its oxidation could be minimal, and hence, the increase in its activation energy of oxidation is relatively lower [67].

\section{Conclusion}

520

The effect of camphor solid and camphor oil addition to diesel on the sooting propensity and their subsequent effect on soot nanostructures were investigated. It was observed through smoke point and TSI measurements that the blending of both camphor solid (up to 5\%) and camphor oil (up to 10\%) could reduce soot formation rate possibly through the improved combustion of the fuel. The subsequent analysis of the produced soot particles through HRTEM, XRD, and Raman studies revealed that soots obtained from the above blends had smaller primary particle diameter with core-shell structure and a greater percentage of short lattice fringes with increased fringe tortuosity as compared to diesel soot. This resulted in an enhancement in the degree of disorder in the crystal structure, thus making it prone to easy attack by $\mathrm{O}_{2}$ during oxidation. Moreover, the presence of higher oxygen and aliphatic contents in soot produced from the blends, as observed through EDX and EELS measurements, resulted in the enhancement of $\mathrm{O}_{2}$-induced soot oxidation kinetics as compared to diesel soot. All the above results therefore confirm that the blending of up to $10 \%$ camphor oil with diesel will not only improve the fuel combustion to reduce soot formation, but would also significantly improve the DPF regeneration efficiency by making soot more susceptible to oxidation.

\section{Supporting Information}

537 A plot showing the measure fuel flow rate as a function of flame height for different fuels and a plot on soot conversion and soot conversion rate at different temperatures and heating rates are provided in the supporting information file.

\section{Acknowledgement}

542 This publication is based upon work supported by the Khalifa University of Science and

543 Technology under Award No. CIRA-2018-99 and Goa University for instrumental facilities 544 (via DST/IMRCD/INNO-INDIGO/BioCFD/2017(G)(ii). G.D.J.P and M.S.C. were supported 
by funding from King Abdullah University of Science and Technology (KAUST), under award number BAS/1/1384-01-01.

\section{References}

[1] J. Bacha, J. Freel, A. Gibbs, L. Gibbs, G. Hemighaus, K. Hoekman, J. Horn, M. Ingham, L. Jossens, D. Kohler, D. Lesnini, J. Mcgeehan, M. Nikanjam, E. Olsen, R. Organ, B. Scott, M. Sztenderowicz, A. Tiedemann, C. Walker, J. Lind, J. Jones, D. Scott, J. Mills, Diesel Fuels Technical Review, Chevron Glob. Mark. (2007) 1-116. doi:10.1063/1.3575169.

[2] I. Dincer, Renewable energy and sustainable development: a crucial review, Renew. Sustain. Energy Rev. 4 (2000) 157-175. doi:10.1016/S1364-0321(99)00011-8.

[3] J.P. Cain, P.L. Gassman, H. Wang, A. Laskin, Micro-FTIR study of soot chemical composition - Evidence of aliphatic hydrocarbons on nascent soot surfaces, Phys. Chem. Chem. Phys. 12 (2010) 5206-5218. doi:10.1039/b924344e.

[4] J.F. Ontiveros-Cuadras, A.C. Ruiz-Fernández, J.-A. Sanchez-Cabeza, J. Sericano, L.H. Pérez-Bernal, F. Páez-Osuna, R.B. Dunbar, D.A. Mucciarone, Recent history of persistent organic pollutants (PAHs, PCBs, PBDEs) in sediments from a large tropical lake, J. Hazard. Mater. 368 (2019) 264-273. doi:10.1016/J.JHAZMAT.2018.11.010.

[5] W.L. Chameides, M. Bergin, Soot Takes Center Stage, Science (80-. ). 297 (2002) 2214 LP - 2215. doi:10.1126/science.1076866.

[6] D. Zhang, Y. Ma, M. Zhu, Nanostructure and oxidative properties of soot from a compression ignition engine : The effect of a homogeneous combustion catalyst, 34 (2013) 1869-1876. doi:10.1016/j.proci.2012.05.096.

[7] A. Brosowski, D. Thrän, U. Mantau, B. Mahro, G. Erdmann, P. Adler, W. Stinner, G. Reinhold, T. Hering, C. Blanke, A review of biomass potential and current utilisation Status quo for 93 biogenic wastes and residues in Germany, Biomass and Bioenergy. 95 (2016) 257-272. doi:10.1016/J.BIOMBIOE.2016.10.017.

[8] K. Shikha, C.Y. Rita, Biodiesel production from non edible-oils: A review, J. Chem. Pharm. Res. 4 (2012) 4219-4230.

[9] A. Karmakar, S. Karmakar, S. Mukherjee, Properties of various plants and animals feedstocks for biodiesel production, Bioresour. Technol. 101 (2010) 7201-7210. doi:10.1016/J.BIORTECH.2010.04.079.

[10] A. Dhar, R. Kevin, A.K. Agarwal, Production of biodiesel from high-FFA neem oil and its performance, emission and combustion characterization in a single cylinder 
DICI engine, Fuel Process. Technol. 97 (2012) 118-129.

doi:10.1016/J.FUPROC.2012.01.012.

581

582

583

584

585

586

587

588

589

590

591

592

593

594

595

596

597

598

599

600

601

602

603

604

605

606

607

608

609

610

611

612

[11] T. Litzinger, M. Stoner, H. Hess, A. Boehman, Effects of oxygenated blending compounds on emissions from a turbocharged direct injection diesel engine, Int. J. Engine Res. 1 (2000) 57-70. doi:10.1243/1468087001545263.

[12] D.D. Das, C.S. McEnally, L.D. Pfefferle, Sooting tendencies of unsaturated esters in nonpremixed flames, Combust. Flame. 162 (2015) 1489-1497. doi:10.1016/J.COMBUSTFLAME.2014.11.012.

[13] F.S. Hirner, J. Hwang, C. Bae, C. Patel, T. Gupta, A.K. Agarwal, Nanostructure characterization of soot particles from biodiesel and diesel spray flame in a constant volume combustion chamber, Fuel. 235 (2019) 130-149. doi:10.1016/j.fuel.2018.07.092.

[14] M.L. Botero, S. Mosbach, J. Akroyd, M. Kraft, Sooting tendency of surrogates for the aromatic fractions of diesel and gasoline in a wick-fed diffusion flame, Fuel. 153 (2015) 31-39. doi:10.1016/j.fuel.2015.02.108.

[15] K. Yehliu, R.L. Vander Wal, O. Armas, A.L. Boehman, Impact of fuel formulation on the nanostructure and reactivity of diesel soot, Combust. Flame. 159 (2012) 35973606. doi:10.1016/J.COMBUSTFLAME.2012.07.004.

[16] T.J. Toops, J.A. Pihl, C.E.A. Finney, J. Gregor, H. Bilheux, Progression of Soot Cake Layer Properties During the Systematic Regeneration of Diesel Particulate Filters Measured with Neutron Tomography, Emiss. Control Sci. Technol. 1 (2015) 24-31. doi:10.1007/s40825-014-0008-1.

[17] R.L. Vander Wal, A. Yezerets, N.W. Currier, D.H. Kim, C.M. Wang, HRTEM Study of diesel soot collected from diesel particulate filters, Carbon N. Y. 45 (2007) 70-77. doi:10.1016/J.CARBON.2006.08.005.

[18] A. Strzelec, T. J. Toops, C. Stuart Daw, Oxygen Reactivity of Devolatilized Diesel Engine Particulates from Conventional and Biodiesel Fuels, Energy \&amp; Fuels. 27 (2013) 3944-3951. doi:10.1021/ef400440a.

[19] M. Çetin, F. Yüksel, H. Kuş, Emission characteristics of a converted diesel engine using ethanol as fuel, Energy Sustain. Dev. 13 (2009) 250-254. doi:10.1016/j.esd.2009.10.001.

[20] P. Pepiot-Desjardins, H. Pitsch, R. Malhotra, S.R. Kirby, A.L. Boehman, Structural group analysis for soot reduction tendency of oxygenated fuels, Combust. Flame. 154 (2008) 191-205. doi:10.1016/J.COMBUSTFLAME.2008.03.017. 
[21] B. Gogoi, A. Raj, M.M. Alrefaai, S. Stephen, T. Anjana, V. Pillai, S. Bojanampati, Effects of 2,5-dimethylfuran addition to diesel on soot nanostructures and reactivity, Fuel. 159 (2015) 766-775. doi:10.1016/j.fuel.2015.07.038.

[22] B. Manoj, A.G. Kunjomana, Study of stacking structure of amorphous carbon by Xray diffraction technique, Int. J. Electrochem. Sci. 7 (2012) 3127-3134.

[23] R.J. Watson, M.L. Botero, C.J. Ness, N.M. Morgan, M. Kraft, An improved methodology for determining threshold sooting indices from smoke point lamps, Fuel. 111 (2013) 120-130. doi:10.1016/j.fuel.2013.04.024.

[24] Dustin Witkowski, Katsufumi Kondo, Gokul Vishwanathan, David Rothamer, Evaluation of the sooting properties of real fuels and their commonly used surrogates in a laminar co-flow diffusion flame, Combust. Flame. 160 (2013) 1129-1141. doi:10.1016/j.combustflame.2013.01.027.

[25] G.D.J. Guerrero Peña, M.M. Alrefaai, S.Y. Yang, A. Raj, J.L. Brito, S. Stephen, T. Anjana, V. Pillai, A. Al Shoaibi, S.H. Chung, Effects of methyl group on aromatic hydrocarbons on the nanostructures and oxidative reactivity of combustion-generated soot, Combust. Flame. 172 (2016) 1-12. doi:10.1016/j.combustflame.2016.06.026.

[26] G. Corro, A. Flores, F. Pacheco-Aguirre, U. Pal, F. Bañuelos, A. Ramirez, A. Zehe, Biodiesel and fossil-fuel diesel soot oxidation activities of $\mathrm{Ag} / \mathrm{CeO} 2$ catalyst, Fuel. 250 (2019) 17-26. doi:10.1016/j.fuel.2019.03.043.

[27] G. Corro, E. Vidal, S. Cebada, U. Pal, F. Bañuelos, D. Vargas, E. Guilleminot, Electronic state of silver in $\mathrm{Ag} / \mathrm{SiO} 2$ and $\mathrm{Ag} / \mathrm{ZnO}$ catalysts and its effect on diesel particulate matter oxidation: An XPS study, Appl. Catal. B Environ. 216 (2017) 1-10. doi:10.1016/j.apcatb.2017.05.059.

[28] G. Corro, N. Sánchez, U. Pal, S. Cebada, J.L.G. Fierro, Solar-irradiation driven biodiesel production using $\mathrm{Cr} / \mathrm{SiO} 2$ photocatalyst exploiting cooperative interaction between Cr6+ and Cr3+ moieties, Appl. Catal. B Environ. 203 (2017) 43-52. doi:10.1016/j.apcatb.2016.10.005.

[29] A.J. Ragauskas, C.K. Williams, B.H. Davison, G. Britovsek, J. Cairney, C.A. Eckert, W.J. Frederick, J.P. Hallett, D.J. Leak, C.L. Liotta, J.R. Mielenz, R. Murphy, R. Templer, T. Tschaplinski, The Path Forward for Biofuels and Biomaterials, Science (80-. ). 311 (2006) 484 LP - 489. doi:10.1126/science.1114736.

[30] M.S. Mettler, D.G. Vlachos, P.J. Dauenhauer, Top ten fundamental challenges of biomass pyrolysis for biofuels, Energy Environ. Sci. 5 (2012) 7797-7809. doi:10.1039/C2EE21679E. 
[31] P. Gallezot, Catalytic Conversion of Biomass: Challenges and Issues, ChemSusChem. 1 (2008) 734-737. doi:10.1002/cssc.200800091.

[32] S.M.A. Rahman, T.J. Rainey, Z. Ristovski, A. Dowell, M.A. Islam, M.N. Nabi, R. Brown, Review on the use of essential oils in compression ignition engines, in: A.K. Agarwal, G. Anirudh, N. Sharma, A.P. Singh (Eds.), Methanol Altern. Fuel Econ., Springer, Singapore, 2019: pp. 157-182. https://eprints.qut.edu.au/122619/.

[33] V.S. Hariharan, K.V. Reddy, K. Rajagopal, Performance, emission and combustion characteristics of sea lemon oil and its diesel blends in a diesel engine, Int. J. Agric. Biol. Eng. 2 (2009) 69-75. doi:10.3965/j.issn.1934-6344.2009.03.069-075.

[34] P.K. Devan, N.V. Mahalakshmi, A study of the performance, emission and combustion characteristics of a compression ignition engine using methyl ester of paradise oileucalyptus oil blends, Appl. Energy. 86 (2009) 675-680. doi:10.1016/J.APENERGY.2008.07.008.

[35] T. Subramanian, E.G. Varuvel, S. Ganapathy, S. Vedharaj, R. Vallinayagam, Role of fuel additives on reduction of NOX emission from a diesel engine powered by camphor oil biofuel, Environ. Sci. Pollut. Res. 25 (2018) 15368-15377. doi:10.1007/s11356-018-1745-4.

[36] G. Kasiraman, B. Nagalingam, M. Balakrishnan, Performance, emission and combustion improvements in a direct injection diesel engine using cashew nut shell oil as fuel with camphor oil blending, Energy. 47 (2012) 116-124. doi:10.1016/j.energy.2012.09.022.

[37] S. Guo, Z. Geng, W. Zhang, J. Liang, C. Wang, Z. Deng, S. Du, The chemical composition of essential oils from Cinnamomum camphora and their insecticidal activity against the stored product pests, Int. J. Mol. Sci. 17 (2016) 1-12. doi:10.3390/ijms 17111836.

[38] H.P. Chen, K. Yang, C.X. You, N. Lei, R.Q. Sun, Z.F. Geng, P. Ma, Q. Cai, S.S. Du, Z.W. Deng, Chemical constituents and insecticidal activities of the essential oil of Cinnamomum camphora leaves against Lasioderma serricorne, J. Chem. 2014 (2014). doi:10.1155/2014/963729.

[39] R. Vallinayagam, S. Vedharaj, W.M. Yang, W.L. Roberts, R.W. Dibble, Feasibility of using less viscous and lower cetane (LVLC) fuels in a diesel engine: A review, Renew. Sustain. Energy Rev. 51 (2015) 1166-1190. doi:10.1016/J.RSER.2015.07.042.

[40] L.J. Martin, Effects of low carbon biofuel blends with Karanja (Pongamia pinnata) Oil Methyl Ester in a Single Cylinder CI Engine on CO2 emission and other performance 
and emission characteristics, Nat. Environ. Pollut. Technol. 15 (2016) 1249-1256.

[41] S. Thiyagarajan, V.E. Geo, L.J. Martin, B. Nagalingam, Simultaneous reduction of NO-smoke-CO2 emission in a biodiesel engine using low-carbon biofuel and exhaust after-treatment system, Clean Technol. Environ. Policy. 19 (2017) 1271-1283. doi:10.1007/s10098-016-1326-5.

[42] W. Ying, L. Genbao, Z. Wei, Z. Longbao, Study on the application of DME/diesel blends in a diesel engine, Fuel Process. Technol. 89 (2008) 1272-1280. doi:10.1016/J.FUPROC.2008.05.023.

[43] Y. Di, C.S. Cheung, Z. Huang, Experimental investigation of particulate emissions from a diesel engine fueled with ultralow-sulfur diesel fuel blended with diglyme, Atmos. Environ. 44 (2010) 55-63. doi:10.1016/J.ATMOSENV.2009.09.039.

[44] H. Song, K.S. Quinton, Z. Peng, H. Zhao, N. Ladommatos, Effects of oxygen content of fuels on combustion and emissions of diesel engines, Energies. 9 (2016) 1-12. doi:10.3390/en9010028.

[45] P. Baskar, A. Senthilkumar, Effects of oxygen enriched combustion on pollution and performance characteristics of a diesel engine, Eng. Sci. Technol. an Int. J. 19 (2016) 438-443. doi:10.1016/J.JESTCH.2015.08.011.

[46] S. Choi, D.E. Lewis, Formation of a dimeric camphor derivative with an unusually stable 3-exo substituent, Tetrahedron. 56 (2000) 8637-8641. doi:10.1016/S00404020(00)00808-5.

[47] J. McNulty, M.J. Millar, G. Bernardinelli, C.W. Jefford, Stereoselective oxidative dimerization of (1R)-camphor. A short synthesis of exo,exo'.3,3'-Biisoborneol, J. Org. Chem. 64 (1999) 5312-5314. doi:10.1021/jo990394g.

[48] X. Wang, C. Song, G. Lv, J. Song, H. Li, B. Li, Evolution of in-cylinder polycyclic aromatic hydrocarbons in a diesel engine fueled with n-heptane and n-heptane/toluene, Fuel. 158 (2015) 322-329. doi:10.1016/J.FUEL.2015.05.053.

[49] M.L. Botero, S. Mosbach, M. Kraft, Sooting tendency of paraffin components of diesel and gasoline in diffusion flames, Fuel. 126 (2014) 8-15. doi:10.1016/j.fuel.2014.02.005.

[50] H.L. Friedman, Kinetics of thermal degradation of char-forming plastics from thermogravimetry. Application to a phenolic plastic, J. Polym. Sci. Part C Polym. Symp. 6 (1964) 183-195. doi:10.1002/polc.5070060121.

[51] S. Vyazovkin, A.K. Burnham, J.M. Criado, L.A. Pérez-Maqueda, C. Popescu, N. Sbirrazzuoli, ICTAC Kinetics Committee recommendations for performing kinetic 
computations on thermal analysis data, Thermochim. Acta. 520 (2011) 1-19. doi:10.1016/J.TCA.2011.03.034.

[52] J.P. Elder, Reconciliation of Arrhenius and iso-conversional analysis kinetics parameters of non-isothermal data, Thermochim. Acta. 272 (1996) 41-48. doi:10.1016/0040-6031(95)02605-3.

[53] J. Rodríguez-Fernández, F. Oliva, R.A. Vázquez, Characterization of the diesel soot oxidation process through an optimized thermogravimetric method, Energy and Fuels. 25 (2011) 2039-2048. doi:10.1021/ef200194m.

[54] X.J. Man, C.S. Cheung, Z. Ning, K.F. Yung, Effect of waste cooking oil biodiesel on the properties of particulate from a DI diesel engine, Aerosol Sci. Technol. 49 (2015) 199-209. doi:10.1080/02786826.2015.1016214.

[55] H.N. Sharma, L. Pahalagedara, A. Joshi, S.L. Suib, A.B. Mhadeshwar, Experimental study of carbon black and diesel engine soot oxidation kinetics using thermogravimetric analysis, Energy and Fuels. 26 (2012) 5613-5625. doi:10.1021/ef3009025.

[56] J. Abboud, J. Schobing, G. Legros, J. Bonnety, V. Tschamber, A. Brillard, G. Leyssens, V. Lauga, E.E. Iojoiu, P. Da Costa, Impacts of oxygenated compounds concentration on sooting propensities and soot oxidative reactivity: Application to Diesel and Biodiesel surrogates, Fuel. 193 (2017) 241-253. doi:10.1016/J.FUEL.2016.12.034.

[57] Y. Jung, C. Bae, Immaturity of soot particles in exhaust gas for low temperature diesel combustion in a direct injection compression ignition engine, Fuel. 161 (2015) 312322. doi:10.1016/J.FUEL.2015.08.068.

[58] G. Barco, A. Maranzana, G. Ghigo, M. Causà, G. Tonachini, The oxidized soot surface: Theoretical study of desorption mechanisms involving oxygenated functionalities and comparison with temperature programed desorption experiments, J. Chem. Phys. 125 (2006). doi:10.1063/1.2360277.

[59] A. Fredrik Ahlström, C.U. Ingemar Odenbrand, Combustion characteristics of soot deposits from diesel engines, Carbon N. Y. 27 (1989) 475-483. doi:10.1016/00086223(89)90080-8.

[60] A. Raj, R. Tayouo, D. Cha, L. Li, M.A. Ismail, S.H. Chung, Thermal fragmentation and deactivation of combustion-generated soot particles, Combust. Flame. 161 (2014) 2446-2457. doi:10.1016/j.combustflame.2014.02.010.

[61] A. Raj, G.R. da Silva, S.H. Chung, Reaction mechanism for the free-edge oxidation of 
soot by O2, Combust. Flame. 159 (2012) 3423-3436.

doi:10.1016/J.COMBUSTFLAME.2012.06.004.

[62] S. V. Chaparala, A. Raj, Reaction mechanism for the oxidation of zigzag site on polycyclic aromatic hydrocarbons in soot by O2, Combust. Flame. 165 (2016) 21-33. doi:10.1016/J.COMBUSTFLAME.2015.09.012.

[63] M.O. Kareem, G.D.J.G. Pena, A. Raj, M.M. Alrefaai, S. Stephen, T. Anjana, Effects of Neem Oil-Derived Biodiesel Addition to Diesel on the Reactivity and Characteristics of Combustion-Generated Soot, Energy and Fuels. 31 (2017) 10822-10832. doi:10.1021/acs.energyfuels.7b01053.

[64] J.P. Szybist, J. Song, M. Alam, A.L. Boehman, Biodiesel combustion, emissions and emission control, Fuel Process. Technol. 88 (2007) 679-691. doi:10.1016/J.FUPROC.2006.12.008.

[65] M.L. Botero, D. Chen, S. González-Calera, D. Jefferson, M. Kraft, HRTEM evaluation of soot particles produced by the non-premixed combustion of liquid fuels, Carbon N. Y. 96 (2016) 459-473. doi:10.1016/j.carbon.2015.09.077.

[66] K. Yehliu, R.L. Vander Wal, A.L. Boehman, Development of an HRTEM image analysis method to quantify carbon nanostructure, Combust. Flame. 158 (2011) 18371851. doi:10.1016/j.combustflame.2011.01.009.

[67] K. Al-Qurashi, A.L. Boehman, Impact of exhaust gas recirculation (EGR) on the oxidative reactivity of diesel engine soot, Combust. Flame. 155 (2008) 675-695. doi:10.1016/j.combustflame.2008.06.002.

[68] A. Raj, S.Y. Yang, D. Cha, R. Tayouo, S.H. Chung, Structural effects on the oxidation of soot particles by O2: Experimental and theoretical study, Combust. Flame. 160 (2013) 1812-1826. doi:10.1016/j.combustflame.2013.03.010.

[69] H.X. Chen, R.A. Dobbins, Crystallogenesis of particles formed in hydrocarbon combustion, Combust. Sci. Technol. 159 (2000) 109-128. doi:10.1080/00102200008935779.

[70] E.A. Belenkov, Formation of graphite structure in carbon crystallites, Inorg. Mater. 37 (2001) 928-934. doi:10.1023/A:1011601915600.

[71] R.H. Hurt, G.P. Crawford, H.-S. Shim, Equilibrium nanostructure of primary soot particles, Proc. Combust. Inst. 28 (2000) 2539-2546. doi:10.1016/S00820784(00)80670-0.

[72] A. Sadezky, H. Muckenhuber, H. Grothe, R. Niessner, U. Pöschl, Raman microspectroscopy of soot and related carbonaceous materials: Spectral analysis and 
structural information, Carbon N. Y. 43 (2005) 1731-1742. doi:10.1016/J.CARBON.2005.02.018.

[73] M. Salamanca, F. Mondragón, J.R. Agudelo, P. Benjumea, A. Santamaría, Variations in the chemical composition and morphology of soot induced by the unsaturation degree of biodiesel and a biodiesel blend, Combust. Flame. 159 (2012) 1100-1108. doi:10.1016/J.COMBUSTFLAME.2011.10.011.

[74] T. Catelani, G. Pratesi, M. Zoppi, Raman characterization of ambient airborne soot and associated mineral phases, Aerosol Sci. Technol. 48 (2014) 13-21. doi:10.1080/02786826.2013.847270.

[75] R. Escribano, J.J. Sloan, N. Siddique, N. Sze, T. Dudev, Raman spectroscopy of carbon-containing particles, Vib. Spectrosc. 26 (2001) 179-186. doi:10.1016/S09242031(01)00106-0.

[76] G.D.J. Guerrero Peña, Y.A. Hammid, A. Raj, S. Stephen, T. Anjana, V. Balasubramanian, On the characteristics and reactivity of soot particles from ethanolgasoline and 2,5-dimethylfuran-gasoline blends, Fuel. 222 (2018) 42-55. doi:10.1016/j.fuel.2018.02.147.

[77] A. Braun, F.E. Huggins, N. Shah, Y. Chen, S. Wirick, S.B. Mun, C. Jacobsen, G.P. Huffman, Advantages of soft X-ray absorption over TEM-EELS for solid carbon studies - a comparative study on diesel soot with EELS and NEXAFS, Carbon N. Y. 43 (2005) 117-124. doi:10.1016/J.CARBON.2004.08.029. 